\title{
How Environmental Protection Motivation Influences on Residents' Recycled Water Reuse Behaviors: A Case Study in Xi'an City
}

\author{
Xiaojun Liu ${ }^{1,+}$, Yuqi He ${ }^{1}$, Hanliang Fu ${ }^{1, *++}+$, Baiyu Chen ${ }^{2}$, Mengmeng Wang ${ }^{1}$ and \\ Zelin Wang ${ }^{3}$ \\ 1 School of Management, Xi'an University of Architecture and Technology, Xi'an 710055, China; \\ xjun_liu@163.com (X.L.); heyuqi7877@163.com (Y.H.); wangmengmeng@live.xauat.edu.cn (M.W.) \\ 2 College of Engineering, University of California Berkeley, Berkeley, CA 94720, USA; baiyu@berkeley.edu \\ 3 School of Humanities and Social Sciences, Xi'an Jiaotong University, Xi'an 710049, China; \\ ai.lee.h.ong@stu.xjtu.edu.cn \\ * Correspondence: fuhanliang@xauat.edu.cn; Tel.: +86-151-1482-7557 \\ + These authors contributed equally to this work.
}

Received: 20 August 2018; Accepted: 17 September 2018; Published: 19 September 2018

\begin{abstract}
Pro-environmental behaviors related to reclaimed water reuse are regarded as important motivations for both environmental protection and the use of reclaimed water, and these motivations could affect the citizens' decision whether they will accept reclaimed water reuse. A hypothesis model was developed as the NAM (Norm Activation Model) has changed, and this hypothesis model was used to explore the factors that affect the citizen's decision about the reclaimed water reuse, and obtain a better understanding of the mechanism of urban citizens in environmental protection and the related outcomes. First, 584 samples were used to verify the reliability and validity of data, and AMOS21.0 was used to test the goodness-of-fit between the sample data and the hypothesis model. Based on this, the applicability of the improved NAM was verified through the study of recycled water reuse. The hypothesis model was used to analyze its direct influences, showing that environmental motivation has positive influences on the citizens' acceptance toward recycled water reuse. Besides, Bootstrap method was used to verify the mediation effect, proving that awareness of consequences regarding environmental pollution caused by human activities and ascription of responsibility could strengthen the citizens' motivation to protect the environment.
\end{abstract}

Keywords: recycled water reuse; environmental protection motivation; structural equation model

\section{Introduction}

Owing to the development of social economy and the growth of population, people have higher life quality requirements. As a result, the consumption of freshwater resources has increased significantly. In the past 100 years, human water demand increased eight times [1]. Human behavior has become the most important factor that affects the natural water-cycling system, and its influence even exceeds the limits of the environmental carrying capability of the earth, and it has brought irreversible damages. [2] The conflict of water supply and demand is very serious in urban areas with concentrated industries and population. Water resource has become an important factor [3] that restricts social and economic development in the 21st century. Therefore, alternative water resources, to supplement freshwater, are necessary to deal with water shortages $[4,5]$.

Currently, the resources that can be used to replace water are desalinated water, rainwater collection, reuse of stormwater, and recycled water [6], among which recycled water is collected from wastewater treatment, is a stable resource and is not affected by seasons compared with stormwater 
and rainwater. Meanwhile, its production requires less energy than desalinated water [7]. Moreover, in the production period, recycled water can relieve the pollution of water environment in local area. However, the public are disgusted by recycled water because its resource is wastewater, so the acceptance degree of recycled water is lower than other water resources, because of health and indoor environmental pollution concerns [8]. Therefore, when recycled water is used as alternative water resource, the acceptance degree of local residents to accept recycled water reuse must be considered seriously $[9,10]$.

By the end of the last century, some scholars already realized the acceptance degree is the biggest obstacle for the publicity of the reuse of recycled water, rather than backward technology [11,12]. Scholars have researched the factors that affect the acceptance degree of recycled water $[13,14]$. Gibson and Burton found the contact degree between the use of recycled water and the human body is an important factor that affects the acceptance degree of the public to recycled water [15]. The public are disgusted with recycled water, which is known as the "yuck factor", regarded as an important index to predict the public attitude and acceptance degree toward the reuse of recycled water [16-18]. Some scholars are committed to predicting the public's attitude toward the reuse of recycled water based on the differences of demographic indicators [19]. Some demographic indexes such as gender, age and education degree are important indicators that can predict the risk perception degree of the public toward the reuse of recycled water [20]. It is found that the public's disgust toward recycled water is positively correlated with their political conservation degree [21].

Besides, other personal factors such as cultural background and values can also influence their decision-making on whether they will use recycled water. Environmental awareness and their attitude to protect environment can be used to predict the acceptance intention of the public toward the reuse of recycled water in some studies [22,23]. The degree of perceived behavioral control of the public toward the reuse of recycled water and their trust on the organization that provide recycled water are important factors that determine whether the public will accept the use of recycled water [24]. Some scholars have found measures to improve the public's trust on water management department, and their acceptance toward the reuse of recycled water, including environmental education [25] and the mutual influences [26] among friends and family members, which improve the possibility for the public to use recycled water. However, few studies have taken the altruistic nature of the reuse of recycled water into consideration and have neglected whether the public's altruistic motivation to protect environment influences their behavior to use recycled water. Thus, in this paper, the altruistic motivation of the public is considered as influential factor of their behavior to use recycled water.

According to the definition of Kollmuss et al., the behavior of individuals to relieve the negative influences their behaviors have on natural environment consciously can be regarded as pro-environmental behaviors [27]. Pro-environmental behaviors consider the nature of environmental protection, which makes it different from common consuming behaviors [28,29]. To some extent, their behaviors are driven by the motivation to protect the environment and do things that benefit society. Therefore, the citizen's behaviors to protect environment can be regarded as reflection of altruistic motivation in the study of pro-environmental behaviors [30,31]. From the research of different scholars on environmental protection behaviors, it can be found they basically agree that environmental protection is an important motivation of residents to join environmental protection activities [32,33]. The reuse of recycled water could reduce the pollution of water environment and increase the supply of water supply, which could further improve the local ecological environment, and even leave precious natural resources for descendants by protecting water and its environment, thus realize the balance among the intergeneration of water resource [34]. Because of the features of recycled water reuse, it is considered in the pro-environmental behavior research [35-37]. Therefore, this research considered the residents' environmental protection motivation as a potential factor that affects the residents' behavior to use recycled water, and studied in-depth its generation mechanism and effectiveness. 


\section{Research Model and Hypotheses}

To find the influencing effect and the generation mechanism of residents' environmental protection behaviors in the reuse of recycled water, Norm Activation Model (NAM) [38] proposed by Schiwartz and colleagues to explain the altruistic motivation of residents' pro-social behaviors was used. In the theoretical frame of NAM, personal norm represents the moral judgment of individuals on behaviors and decisions, determines whether residents make moral judgments on altruistic behaviors, and further affects the final behaviors of residents. Personal norm is activated by individual perception about the possible consequences of behaviors that might do harm to society and attribution of responsibility about bad consequences. Therefore, personal norm, consequence awareness and the attribution of responsibility are three major elements of NAM, which constitute the basic theoretical model, as shown in Table 1.

Table 1. Variable definition of NAM.

\begin{tabular}{cc}
\hline Variable Name & Variable Definition \\
\hline Personal Norm & Could drive residents to carry out or avoid the moral norms of \\
specific behaviors
\end{tabular}

NAM has been used to explain pro-environmental behaviors and its prediction effect has been recognized in numerous studies, but there are different opinions about the major components of the model, and it can be concluded as three types below:

Consequence awareness and attribution of responsibility have been regarded as the moderating variable that is used to regulate the influence of behavior decision. In this opinion, it is believed that personal regulation has objective influence on behavior decision, but the consequence perception and attribution of responsibility are not taken as the starting condition for personal moral rules; instead, they are regarded as the moderating variable that could affect the influence degree of personal norms on behavior decision. The mutual influences among latent variables can be found in Figure 1a.

Consequence awareness, attribution of responsibility and personal norms and behavior decisions have been regarded as distant intermediary model that affect behavior decisions. This opinion affirms the intermediary effect of personal norms on the attribution of responsibility and behavior decision influence. Meanwhile, it is believed that the consequence awareness will have direct influence of personal norms and will affect behavior decision indirectly. The mutual influences of latent variables can be found in Figure 1b.

Consequence awareness and attribution of responsibility are the theoretical models for the influence factors of personal norms. In this opinion, the negative consequences of behaviors and attribution of responsibility are starting conditions for the regulation of personal moral rules. Besides, the consequence awareness of personal norms and attribution of responsibility are regarded as the attribution of responsibility that affects behavior decision indirectly. The mutual influences among latent variables are shown in Figure 1c.

Based on previous studies on NAM, it can be found that personal norms have direct effects on pro-social behaviors. However, researchers have different opinions about the relation of attribution of responsibility, consequence awareness and personal norms. We believe that personal ethics can be fully activated as long as residents admit their behaviors have negative influence on others and think they should take responsibility for the consequences. In this way, they will present pro-social behaviors or pro-environmental behaviors. Meanwhile, we think consequence awareness will affect the residents' judgment on who is responsible. 
NAM has been improved based on self-completion theory. According to self-completion theory, residents tend to set up goals that suit their identities, and usually have a strong desire to make the outcome conform to their identities through compensatory measures if they fail to reach their goals. Numerous studies show this can protect their moral image [39]. Residents' attitude toward environment belongs to an element of personal moral image. According to self-completion theory, residents will have strong desire to make their behaviors coincide with their moral images. Therefore, when local residents realize the damages they bring to their environment, they tend to perform compensatory environmental protections to maintain their moral images [40]. Studies have shown that people tend to take compensatory measures and choose a green diet [41] when they recall what they did has destroyed the environment. In this research context, when residents understand the serious consequences of their actions on water environment, the compensatory measure they can take is to accept and reuse recycled water. Thus, the modified standard activation model (improved norm activation model) can be found in Figure 1d.

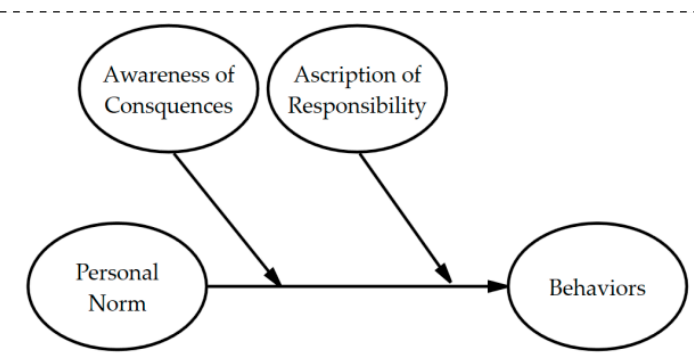

(a) Logic frame diagram of norm activation model with moderating variables

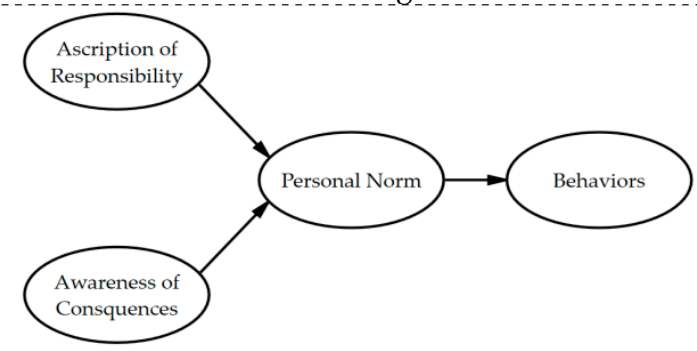

(c) Logic frame diagram of norm activation model with one mediating variable

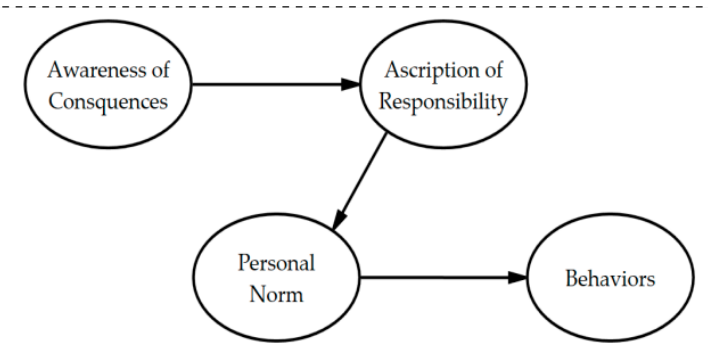

(b) Logic frame diagram of norm activation model with two mediating variables

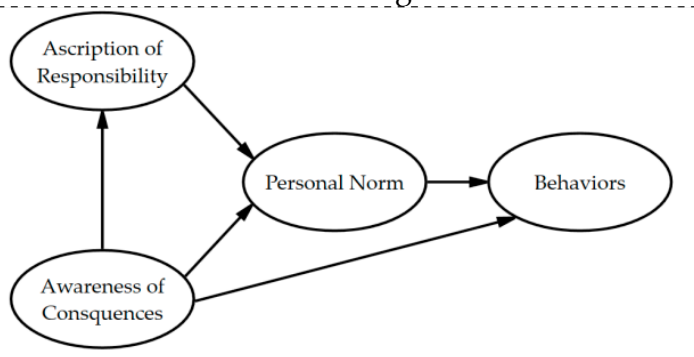

(d) Logic frame diagram of improved norm activation model

Figure 1. Logic frame diagram. Note: Conclusions based on studies by Chaisamrej et al. and Osterhus [42].

This study used first-hand data as reference and combined them with the characteristics in the field of the reuse of recycled water to establish a NAM that is suitable for the reuse of recycled water. Quantitative analysis was made regarding the direct and indirect influence of different indicators in the model, which was then used to verify what influence environmental protection motivation has on the decision making process of urban residents for the reuse of recycled water and to explain the generation mechanism. Combined with the characteristics of reclaimed water reuse, consequence awareness is defined as the residents' awareness about water pollution caused by human activity. The attribution of responsibility has been defined as the residents' attribution of responsibility regard to water pollution. Meanwhile, according to the definition of personal norms, the variable definition of personal norms was defined as the motivation of residents to protect water environment. Based on this understanding, a NAM was designed for the reuse of recycled water (see Figure 2). 


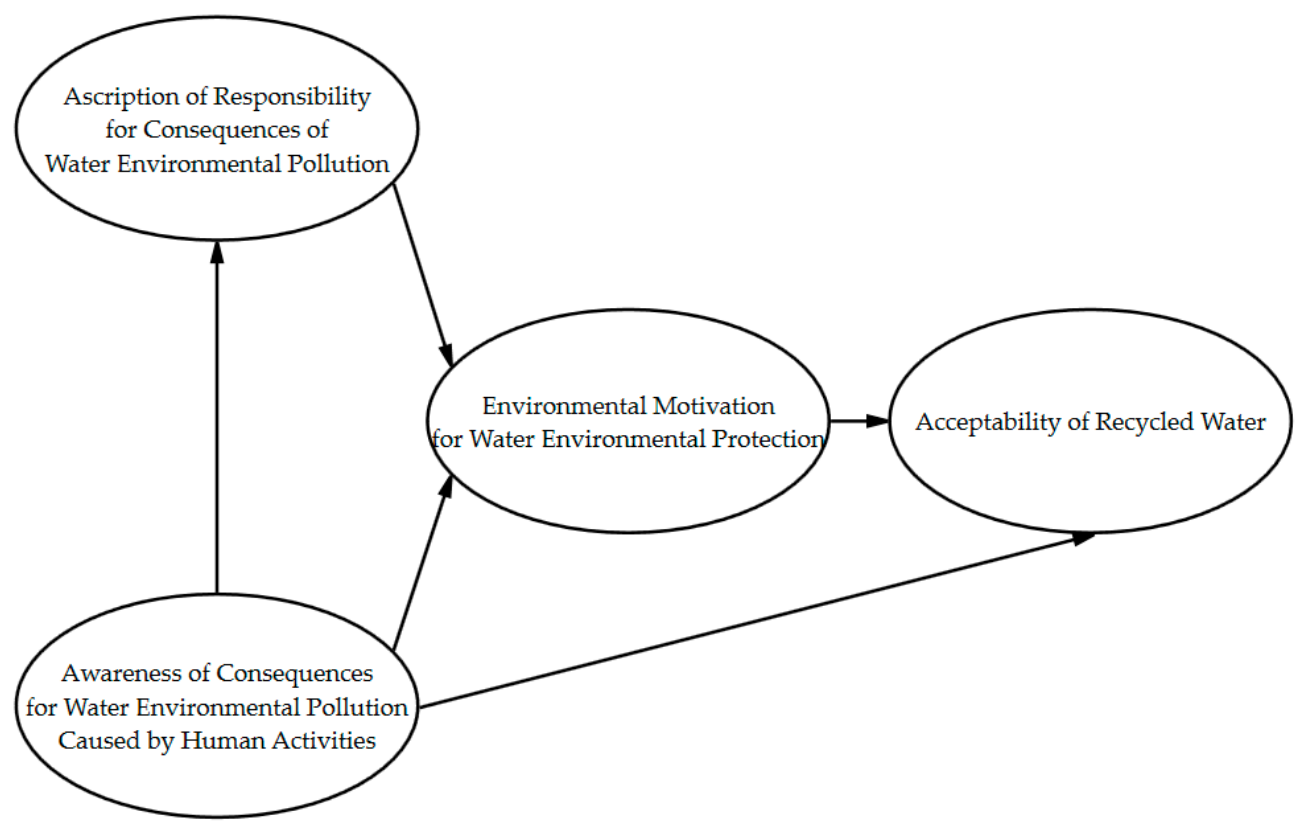

Figure 2. Logic frame diagram of recycled water reuse behavior NAM.

In view of the characteristics of the reuse of recycled water, the NAM was improved. First, whether the data of the survey on the urban residents' willingness to accept reuse of recycled water have good fitting degree was confirmed.

Therefore, the corresponding assumptions are proposed in this paper.

Assumption 1. The improved NAM is suitable for the study on the reuse of recycled water.

Within the model framework, assumptions about the motivation of water environment protection were proposed to explore different influence paths for the residents' acceptance toward the reuse of recycled water to use it as scientific reference to confirm the generation of the motivation to protect the environment in the reuse of recycled water and corresponding effect mechanism.

Assumption 2. The residents' attribution of responsibility about water environment pollution has positive effect on the motivation to protect water environment.

Assumption 3. The consequence awareness of the residents about water pollution caused by human activities has positive effect on their motivation to protect water environment.

Assumption 4. The consequence awareness of the residents about the water pollution caused by human activities has positive effect on their acceptance to use the recycled water.

Assumption 5. The residents' attribution of responsibility about water environment pollution has positive effect on the motivation to protect water environment, and has indirect positive effect on their acceptance to use recycled water.

Assumption 6. The consequence awareness of the residents about the water pollution caused by human activities has positive effect on their motivation to protect water environment by affecting their attribution of responsibility about water environment pollution indirectly.

Assumption 7. The consequence awareness of the residents about the water pollution caused by human activities has positive effect on their motivation to protect water environment and thus indirect influence on their acceptance toward the reuse of recycled water.

Assumption 8. The consequence awareness of the residents about the water pollution caused by human activities has positive effect on their attribution of responsibility and motivation to protect water environment successively, and has positive long-distance intermediary influence on their acceptance. 


\section{Methodology}

\subsection{Data Collection}

To acquire data for the study, a survey was performed in $\mathrm{Xi}^{\prime}$ an. First, ten investigators received trainings about related basic knowledge. During the period of 16 September-16 October 2016, random investigations were made in the street, central plaza, shopping mall, and parks within different districts and counties in Xi'an. The research sites can be found in Figure 3.

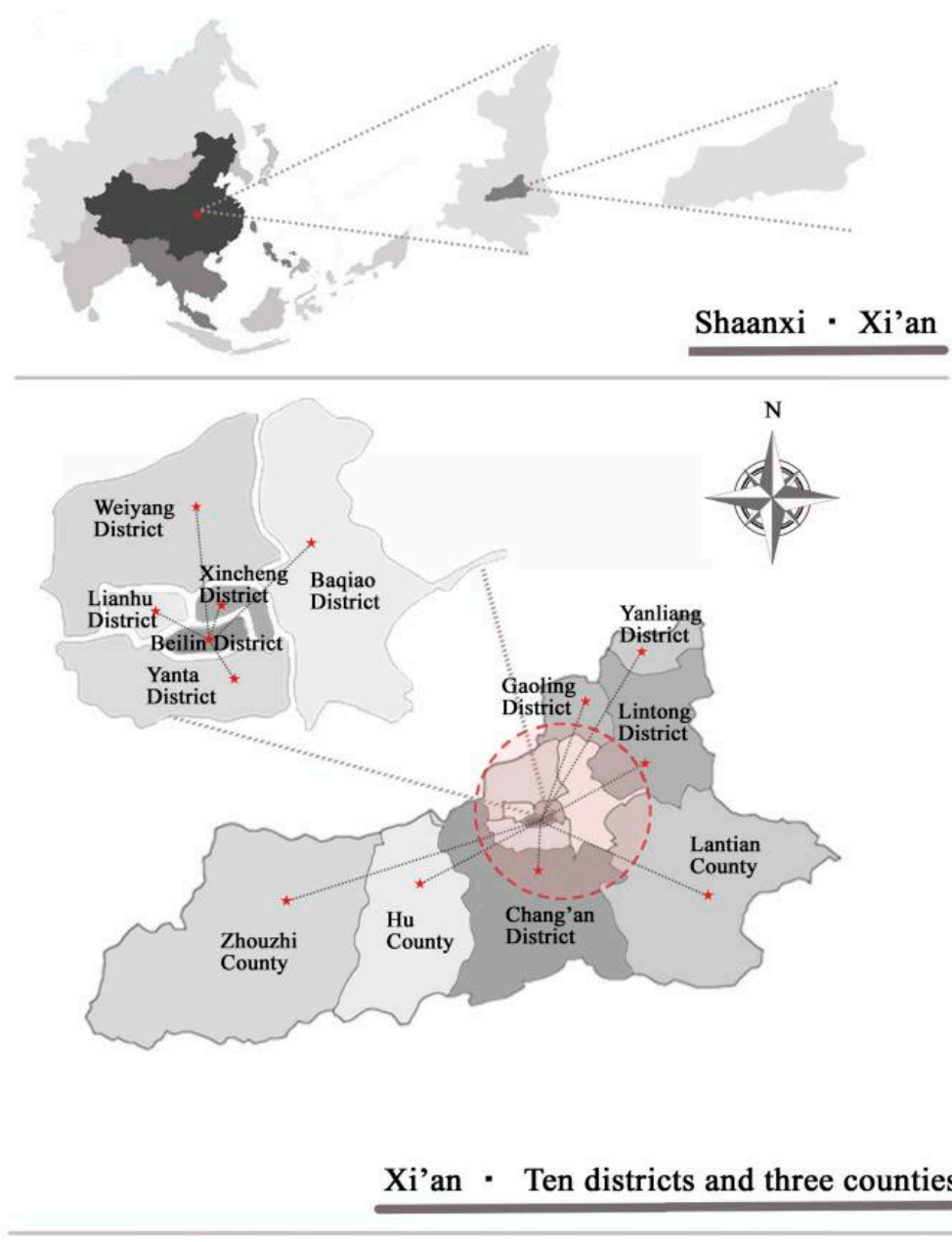

Figure 3. Research sites.

In total, 714 questionnaires were released, and 584 questionnaires were collected, thus the efficiency rate of the questionnaire is $82 \%$. The basic information about the questionnaire participants are shown in Table 2. Every participant was given one gift as souvenir [43]. 
Table 2. Research sample description table.

\begin{tabular}{ccc}
\hline Variable Name & Variable Description & Total \\
\hline \multirow{2}{*}{ Age } & $\geq 43$ & 120 \\
& $<43$ & 454 \\
\hline \multirow{2}{*}{ Gender } & Male & 127 \\
& Female & 447 \\
\hline \multirow{2}{*}{ Educational background } & Bachelor degree or above & 301 \\
& Other & 280 \\
\hline
\end{tabular}

Note: To avoid antipathy of the survey participants, private information is not compulsory, so some questionnaires were found to be blank in this part. In many conditions, people are divided into two stages of age in China, young and old, and 43 is always the age line [44].

\subsection{Questionnaire Design}

In the process of questionnaire design, researchers spent much time and energy finding existing questionnaires in this field or in related fields to improve the validity and reliability of the questionnaire [45-48]. Afterward, researchers referred to those questionnaires and then designed the questionnaire that was used in this study. All data were obtained on a seven-point Likert scale.

ACC (Acceptability of Recycled Water). To find the most proper indicators to measure the public's acceptance toward reclaimed water reuse, the researchers referred to the classification of sewage recycling types in the city sewage. Meanwhile, the different types of facilitates in cities were used as evaluation indicators to measure the public's acceptance toward reclaimed water reuse. The measurement table for ACC is shown in Table 3.

Table 3. Measurement table for ACC.

\begin{tabular}{cccc}
\hline $\begin{array}{c}\text { Latent } \\
\text { Variable }\end{array}$ & $\begin{array}{c}\text { Conceptual } \\
\text { Interpretation }\end{array}$ & Question No. & Question Item \\
\hline & & ACC 1 & Use recycled water for residential toilet flushing. \\
& Acceptability of & ACC 2 & Use recycled water for urban road sprinkling. \\
ACC & ACC 3 & Use recycled water for firefighting. \\
& recycled water & ACC 4 & Use recycled water for residential greening. \\
& & ACC 5 & Use recycled water for car washing. \\
\hline
\end{tabular}

AOC (Awareness of Consequences for the water environmental pollution caused by human activities). According to the Schwartz, AOC can be explained as the awareness of possible harms that can be made on others because of personal behaviors [49]. Considering of the function of recycled water in improving water environment, the awareness of consequence owing to human activities to water environment was measured. The measurement table for AOC is shown in Table 4.

Table 4. Measurement table for AOC.

\begin{tabular}{|c|c|c|c|}
\hline $\begin{array}{c}\text { Latent } \\
\text { Variable }\end{array}$ & $\begin{array}{l}\text { Conceptual } \\
\text { Interpretation }\end{array}$ & Question No. & Question Item \\
\hline \multirow{3}{*}{$\mathrm{AOC}$} & \multirow{3}{*}{$\begin{array}{l}\text { Awareness of } \\
\text { consequences for the } \\
\text { water environmental } \\
\text { pollution caused by } \\
\text { human activities }\end{array}$} & AOC 1 & $\begin{array}{l}\text { The pollutant caused by human activities could } \\
\text { destroy the living environment of aquatic animals }\end{array}$ \\
\hline & & AOC 2 & $\begin{array}{l}\text { Immoderate sewage discharge is an important } \\
\text { factor of the water environment pollution }\end{array}$ \\
\hline & & AOC 3 & $\begin{array}{l}\text { The discharge of chemicals in our daily life like } \\
\text { washing powder and abstergent could have } \\
\text { serious pollution on water environment }\end{array}$ \\
\hline
\end{tabular}


AOR (Ascription of Responsibility for the consequences of water environmental pollution). Referring to Schwartz, and combining the features of the industry in the use of recycled water, the definition of responsibility has been specified to the responsibilities about the damage and protection of water environment in urban cities. The measurement table for AOR is shown in Table 5.

Table 5. Measurement table for AOR.

\begin{tabular}{cccl}
\hline $\begin{array}{c}\text { Latent } \\
\text { Variable }\end{array}$ & $\begin{array}{c}\text { Conceptual } \\
\text { Interpretation }\end{array}$ & $\begin{array}{c}\text { Question } \\
\text { No. }\end{array}$ & Question Item \\
\hline AOR & $\begin{array}{c}\text { Ascription of } \\
\text { responsibility for the } \\
\text { consequences of water } \\
\text { environmental } \\
\text { pollution }\end{array}$ & AOR 1 & $\begin{array}{l}\text { Everyone of us shall be responsible for the damage } \\
\text { and pollution of water environment in the city we live }\end{array}$ \\
\cline { 3 - 4 } & AOR 2 & $\begin{array}{l}\text { All urban residents shall take the responsibility to } \\
\text { protect the water environment in the city we live }\end{array}$ \\
\cline { 3 - 4 } & AOR 3 & $\begin{array}{l}\text { Everyone of us are responsible for the damage of water } \\
\text { environment in the city we live }\end{array}$ \\
\hline
\end{tabular}

Note: The research that is referred in the design of this part [51].

EM (Environmental Motivation for water environmental protection). The moral obligation in this study has been defined as the obligation to reduce pollutant discharge and protect the water environment in regions. The measurement table for EM is shown in Table 6.

Table 6. Measurement table for EM.

\begin{tabular}{cccl}
\hline Latent & $\begin{array}{c}\text { Conceptual } \\
\text { Variable }\end{array}$ & Question No. & \multicolumn{1}{c}{ Question Item } \\
\hline & & EM 1 & $\begin{array}{l}\text { I think I have the moral obligation to protect the } \\
\text { water environment }\end{array}$ \\
\cline { 3 - 4 } EM & $\begin{array}{c}\text { Environmental } \\
\text { motivation for Water } \\
\text { environmental } \\
\text { protection }\end{array}$ & EM 2 & $\begin{array}{l}\text { I think I should protect the water environment in } \\
\text { this place }\end{array}$ \\
\cline { 3 - 4 } & EM 3 & $\begin{array}{l}\text { I think all of us should reduce the pollution of water } \\
\text { environment in our daily life }\end{array}$ \\
\cline { 3 - 4 } & EM4 & $\begin{array}{l}\text { Base on my personal values, I have the responsibility } \\
\text { and obligation to protect water environment }\end{array}$ \\
\hline
\end{tabular}

Note: The design of this part of the questionnaire refers to Ref. [52].

\section{Results and Discussion}

Two models were used in SEM analysis: measurement narrates corresponding items and structural model explains different latent constructs. Measurement model and structural model are usually analyzed in two stages, so we first analyzed the validity of measurement model, and then assessed the structural model to test the hypotheses of this research [53].

\subsection{Measurement Model}

In designing the structural equation model, Bentler's advice was adopted. Samples were separated into two parts to guarantee the credibility of the structural equation model: one was used for the development of the model, while the other part was used to validate the model repeatedly [54]. Thus, 584 valid samples were divided into two parts [55]: 292 samples were used to develop the mode, while the remaining samples were used to verify the model repeatedly. As Hair et al. mentioned, the ratio between the samples and the observed variables in the structural equitation model basically is within 1:10-1:15, and between 200 and 400 samples are appropriate [56]. This research included four latent variables with 15 questions. Thus, to meet the requirements of sample number, 292 samples were used in the model development. 
In the test of convergence validity, the tester adopted the suggestions of Fornell and Larcker. As a result, the standardized factor loading, combined reliability (CR) and average variance extraction (AVE) and other indicators were observed (please see Table 7 for the specific test values). From the test results in Table 6, all standardized factor loading are greater than 0.6 , and the non-standardized tests are also important and obvious. Moreover, it was found that the CR values are greater than 0.7 , which meets the expectation of Fornell and Larcker, and Hair. Meanwhile, the AVE values are greater or close to 0.5 , which also meet the recommended standard of Fornell and Larcker. Therefore, it can be summarized that each latent variable in the research has good convergent validity [57].

Table 7. Results for the measurement model.

\begin{tabular}{|c|c|c|c|c|c|c|c|c|c|}
\hline \multirow{2}{*}{$\begin{array}{c}\text { Latent } \\
\text { Variable }\end{array}$} & \multirow{2}{*}{ Title } & \multicolumn{4}{|c|}{ Estimation of Parameter Significance } & \multirow{2}{*}{$\begin{array}{c}\begin{array}{c}\text { Factor } \\
\text { Loading }\end{array} \\
\text { Std. }\end{array}$} & \multirow{2}{*}{$\begin{array}{c}\begin{array}{c}\text { Question } \\
\text { Reliability }\end{array} \\
\text { SMC }\end{array}$} & \multirow{2}{*}{$\begin{array}{c}\text { Composite } \\
\text { Reliability }\end{array}$} & \multirow{2}{*}{$\begin{array}{c}\begin{array}{c}\text { Convergent } \\
\text { Validity }\end{array} \\
\text { AVE }\end{array}$} \\
\hline & & Unstd & S.E. & $t$-Value & $p$ & & & & \\
\hline \multirow[b]{2}{*}{ ACC } & ACC2 & 1.085 & 0.042 & 25.745 & $* * *$ & 0.917 & 0.841 & & \\
\hline & ACC3 & 1.012 & 0.041 & 24.407 & $* * *$ & 0.899 & 0.808 & & \\
\hline \multirow{4}{*}{ EM } & EM1 & 1.000 & & & & 0.868 & 0.753 & 0.907 & 0.710 \\
\hline & EM2 & 0.912 & 0.046 & 19.829 & $* * *$ & 0.891 & 0.794 & & \\
\hline & EM3 & 0.832 & 0.052 & 15.853 & $* * *$ & 0.773 & 0.598 & & \\
\hline & EM4 & 0.928 & 0.052 & 17.888 & $* * *$ & 0.833 & 0.694 & & \\
\hline \multirow[t]{2}{*}{ AOC } & AOC2 & 1.319 & 0.144 & 9.175 & $* * *$ & 0.879 & 0.773 & & \\
\hline & AOC3 & 1.021 & 0.108 & 9.462 & $* * *$ & 0.659 & 0.434 & & \\
\hline
\end{tabular}

Note: ${ }^{* * *}$ Significant at $p<0.001$.

It is required to find out whether the square root of the AVE value for corresponding latent variable is greater than other latent variables and other related coefficients based on the findings in discriminate validity test according to Fornell and Larckers' recommendations. Therefore, in Table 8, it can be seen that the latent variables of the questionnaire have better discriminate validity.

Table 8. Discriminant validity for the measurement model.

\begin{tabular}{cccccc}
\hline & AVE & AOR & AOC & EM & ACC \\
\hline AOR & 0.671 & $\mathbf{0 . 8 1 9}$ & & & \\
AOC & 0.554 & 0.578 & $\mathbf{0 . 7 4 4}$ & & \\
EM & 0.710 & 0.639 & 0.419 & $\mathbf{0 . 8 4 3}$ & \\
ACC & 0.816 & 0.351 & 0.400 & 0.478 & $\mathbf{0 . 9 0 3}$ \\
\hline
\end{tabular}

Notes: The square root of AVE between the corresponding latent variables and the remaining variables are in bold, and this can be regarded as Pearson correlation values between latent variables.

\subsection{Structural Model}

AMOS21.0 was used to test 292 samples (see Figure 4) and the data mentioned in this section based on the verified reliability and validity of the data and the sample numbers. Besides, it also verified the model simulation. Afterward, 292 remaining samples were used in the verification of recycled water NAM repeatedly, which demonstrated the previous eight assumptions. Moreover, the intermediary effect on the model was also analyzed. The structure model results are shown in Figure 4. 


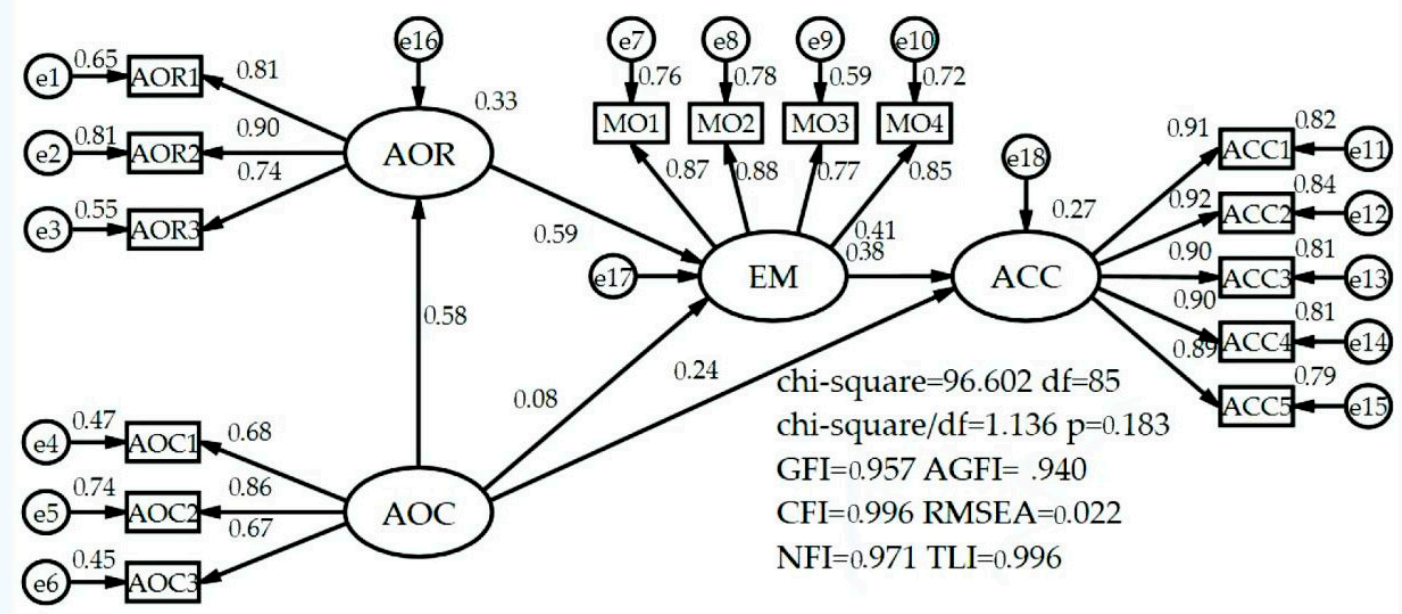

Figure 4. Recycled water NAM.

\subsubsection{Model Fit Analysis}

To test the goodness-of-fit of this model, we first need verified the theory with the structure equation. If a better goodness-of-fit was obtained, it means the simulation model is very similar to the actual situation of the sample. The structural equation was used in many studies according to the review published by Jackson et al. [58]. Ten indicators were involved in various studies related to fitting index, namely Chi-square, Degrees of freedom (df), Chi-square/df ratio, Root-mean-square error of approximation (RMSEA), Standardized RMR; Goodness of fit index (GFI), Adjusted GFI, Normed fit index (NFI), Tucker-Lewis index (TLI) and Comparative fit index (CFI), which are ranked based on the frequency order in the report [58]. Thus, these 10 indicators were also used in this study. Table 9 shows the specific fit indexes.

Table 9. Model fitting table.

\begin{tabular}{ccccccccccc}
\hline Fitting Index & Chi-Square & df & Chi-Square/df & RMSEA & SRMR & GFI & AGFI & NFI & TLI & CFI \\
\hline Measurement value & 96.602 & 85 & 1.136 & 0.022 & 0.031 & 0.996 & 0.940 & 0.971 & 0.996 & 0.996 \\
\hline
\end{tabular}

Therefore, the structural equation model has good fitting indexes, indicating that the model fits the data well.

\subsubsection{Cross-Validity Analysis and Hypothesis Testing}

To test the cross-validity of the structural equation model, the group comparison method was used, so 292 samples can be distributed randomly into the model, and a comparison can be made between this model and the present mode to confirm the cross-group consistency of the structural equation model. In testing the cross-group consistency, a tight replication strategy was used. This test involves several issues, namely, whether the factor loading (Measurement Weights) is congruent, whether the path coefficients (Structural Weights) are congruent, whether the factor co-variances (Structural Co-variances) are congruent, and whether the structural residuals (Structural Residuals) and measurement residuals (Measurement Residuals) are congruent. If the factor loading in the two groups of models is the same and the model is right, then the test result will be $p=0.168$, which is greater than 0.05 . It proves that cross-group consistency exists in the factor loading of the structural model. Thus, to verify the consistency of the factor loading, we assumed the path coefficients are consistent, so the test resulting $p$ is 0.464 , which is greater than 0.05 . Therefore, it can be seen that the factor covariance of the structural model has cross-group consistency. Thus, assuming the 
structural residuals in the model are congruent, then the rest resulting $p$ is 0.476 , which is greater than 0.05 , which proves cross-group consistency also exists in the structural residuals of the structural model. Finally, we assumed the measurement residuals of the model are also congruent based on the assumptions we mentioned above. Although the test resulting $p$ is 0.000 , which is less than 0.05 , both the absolute values of $\triangle \mathrm{CFI}$ and $\Delta \mathrm{TLI}$ are less than 0.01 . Therefore, we can conclude that the measurement residuals of the structural model also have cross-group consistency in actual situations based on Little's recommendations [59]. With strict strategy used in the group consistency test, most indexes in the model are congruent, so cross-group consistency exists in the two groups within the structural model. That is, the structural equation model already passed the test of cross validity, and the model settings are right.

After making model fit analysis, it can be found that structural equation model has great effect on the recovery of original data. Meanwhile, from the results of cross-validity analysis, it was found that the model can keep great consistency among sample groups that are divided randomly. Therefore, Assumption 1 that represents the model fit degree is valid, that is, the improved NAM is suitable for the study on the reuse of recycled water.

\subsubsection{Direct Effect Analysis and Hypothesis Testing}

The path coefficient was found after verifying the adaptability of the structural model in the research on the reuse of the recycled water and then verifying corresponding assumptions. The path coefficient for the structural model is shown in Table 10.

Table 10. Path coefficient for the structural model.

\begin{tabular}{ccccccc}
\hline Path Name & $\begin{array}{c}\text { Standardized } \\
\text { Estimated Value }\end{array}$ & $\begin{array}{c}\text { Non-Standardized } \\
\text { Estimated Value }\end{array}$ & $\begin{array}{c}\text { Standard } \\
\text { Error }\end{array}$ & $\boldsymbol{t}$-Value & $\boldsymbol{p}$ & Significance \\
\hline $\mathrm{AOC} \rightarrow \mathrm{AOR}$ & 0.576 & 0.583 & 0.080 & 7.316 & $* * *$ & Significant \\
$\mathrm{AOC} \rightarrow \mathrm{EM}$ & 0.077 & 0.075 & 0.071 & 1.057 & 0.291 & Non-significant \\
$\mathrm{AOR} \rightarrow \mathrm{EM}$ & 0.593 & 0.569 & 0.076 & 7.509 & $* * *$ & Significant \\
$\mathrm{EM} \rightarrow$ ACC & 0.376 & 0.867 & 0.148 & 5.875 & $* * *$ & Significant \\
$\mathrm{AOC} \rightarrow$ ACC & 0.239 & 0.535 & 0.151 & 3.541 & $* * *$ & Significant \\
\hline
\end{tabular}

Note: ${ }^{* * *}$ Significant at $p<0.001$.

According to Table 10, the path coefficient of different dimensions in the structural equation model has no significant influences on the AOC of water pollution and the motivation to protect water environment. However, the other paths have significant effect on them, that is, there is significance influence among corresponding latent variables.

According to the significance testing of path coefficient results, it can be found that the attribution of responsibility about water pollution has positive effect on the motivation to protect water environment. Meanwhile, the AOC of the residents about the water pollution caused by human activities have positive effect on their acceptance to use recycled water, so Assumptions 2 and 4 are valid. However, the residents' AOC regarding to the water pollution caused by human activities does not have significant effect on their motivation to protect water environments, so Assumption 3 is invalid.

\subsubsection{Meditation Effect Analysis and Hypothesis Testing}

The mediation effect is a critical statistical concept, and it has been applied in social sciences frequently. Many scholars in this field collected relevant articles that were published in the two top journals of social psychology from the period of 2005 to 2009 and found $59 \%$ and $65 \%$ of the articles in the two journals use the mediation effect test [60]. The application of the mediation effect has helped researchers to understand the influence and working mechanism of independent variables on dependent variables better. In the test of mediation effect, Hayes's suggestion was adopted and the bootstrap method was used [61]. 
(1) Testing of the mediation effect between AOR and ACC

According to the theoretical model, AOR only has one path AOR $\rightarrow \mathrm{EM} \rightarrow \mathrm{ACC}$, and Bootstrap was used to judge whether this mediating effect is partial or complete. The mediation effect between AOR and ACC is shown in Table 11.

Table 11. Test table of the mediation effect between AOR and ACC.

\begin{tabular}{|c|c|c|c|c|c|c|}
\hline \multirow{3}{*}{ Point Estimate } & \multirow{2}{*}{\multicolumn{2}{|c|}{ Product of Coefficients }} & \multicolumn{4}{|c|}{ Bootstrapping } \\
\hline & & & \multicolumn{2}{|c|}{ BC $95 \%$ CI } & \multicolumn{2}{|c|}{ Percentile 95\% CI } \\
\hline & SE & $\mathrm{Z}$ & Lower & Upper & Lower & Upper \\
\hline \multicolumn{7}{|c|}{ Indirect Effect } \\
\hline 0.305 & 0.104 & 2.933 & 0.171 & 0.618 & 0.153 & 0.554 \\
\hline \multicolumn{7}{|c|}{ Direct Effect } \\
\hline 0.066 & 0.086 & 0.767 & -0.105 & 0.235 & -0.103 & 0.242 \\
\hline \multicolumn{7}{|c|}{ Total Effect } \\
\hline 0.371 & 0.089 & 4.169 & 0.237 & 0.599 & 0.230 & 0.573 \\
\hline
\end{tabular}

Note: BC, CI, Indirect Effect and Direct effect refer to Bias-corrected, confidence interval, path AOR $\rightarrow \mathrm{EM} \rightarrow \mathrm{ACC}$ and path $\mathrm{AOR} \rightarrow \mathrm{ACC}$, respectively, while samples in the test were obtained from 5000 times of Bootstrap.

In Table 11, the $\mathrm{Z}$ value of the path AOR $\rightarrow$ ACC is less than 1.96, which means this path has significant mediation effect through coefficient product method. Meanwhile, the bootstrap method shows the minimal value and maximal value of $\mathrm{BC}$ method and percentile methods contain zero. Therefore, we confirmed path AOR $\rightarrow$ ACC does not have significant mediation effect.

Meanwhile, the path AOR $\rightarrow \mathrm{EM} \rightarrow \mathrm{ACC}$ and the overall effect are significant $(Z$ value is greater than 1.96 and 0 is not included between Bias-corrected and Percentile), which means AOR $\rightarrow \mathrm{EM} \rightarrow \mathrm{ACC}$ has a complete mediating effect.

From the testing of Mediating Effect, it can be seen that the residents' attribution of responsibility for the water pollution will have positive effect on their motivation to protect water environment and then have positive mediating effect on their acceptance toward the use of recycled water indirectly, so Assumption 5 is valid.

(2) Testing of the mediation effect between AOC and EM

According to the theoretical model, the AOR can affect the EM through two paths: $\mathrm{AOC} \rightarrow \mathrm{AOR} \rightarrow \mathrm{EM}$ and $\mathrm{AOC} \rightarrow \mathrm{EM}$. Bootstrap was used to test the existence of mediating effect on the two paths. The mediation effect between AOC and EM is shown in Table 12.

Table 12. Test table of the mediation effect between AOC and EM.

\begin{tabular}{|c|c|c|c|c|c|c|}
\hline \multirow{3}{*}{ Point Estimate } & \multirow{2}{*}{\multicolumn{2}{|c|}{ Product of Coefficients }} & \multicolumn{4}{|c|}{ Bootstrapping } \\
\hline & & & \multicolumn{2}{|c|}{ BC $95 \%$ CI } & \multicolumn{2}{|c|}{ Percentile $95 \%$ CI } \\
\hline & $\mathrm{SE}$ & $\mathbf{Z}$ & Lower & Upper & Lower & Upper \\
\hline \multicolumn{7}{|c|}{ Indirect Effect } \\
\hline 0.534 & 0.159 & 3.358 & 0.289 & 0.943 & 0.256 & 0.883 \\
\hline \multicolumn{7}{|c|}{ Direct Effect } \\
\hline-0.135 & 0.207 & -0.652 & -0.547 & 0.264 & -0.556 & 0.259 \\
\hline \multicolumn{7}{|c|}{ Total Effect } \\
\hline 0.399 & 0.203 & 1.966 & 0.033 & 0.834 & -0.002 & 0.796 \\
\hline
\end{tabular}

Note: $\mathrm{BC}$ is Bias-corrected; $\mathrm{CI}$ represents confidence interval; Indirect Effect refers to path $\mathrm{AOC} \rightarrow \mathrm{AOR} \rightarrow \mathrm{EM}$; Direct Effect refers to path $\mathrm{AOC} \rightarrow \mathrm{EM}$; and samples were obtained by 5000 times of Bootstrap. 
$\mathrm{Z}$ value of path $\mathrm{AOC} \rightarrow \mathrm{EM}$ is less than 1.96 based (Table 12), which means the path has significant mediation effect based on the coefficient product methods. Meanwhile, with the bootstrap method, we found both the minimal value and maximal value of the bias-corrected method and the percentile method includes 0 .

Thus, AOC does not have significant direct effect on EM. Meanwhile, the path AOC $\rightarrow \mathrm{AOR} \rightarrow \mathrm{EM}$ and overall effect is significant ( $\mathrm{Z}$ value is greater than 1.96, and 0 is not included between Bias-corrected and Percentile), which means, although AOC does not have significant direct effect on EM, it still has a direct effect on $\mathrm{EM}$ through $\mathrm{AOR}$, so $\mathrm{AOC} \rightarrow \mathrm{AOR} \rightarrow \mathrm{EM}$ is a compete mediation.

From the testing of mediating effect, it was found that the resident's AOC toward water pollution caused by human activities has positive effect on their attribution of responsibilities, and an indirect positive effect on their motivation to protect water environment, which means it has positive mediating effect, so Assumption 6 is valid.

(3) Testing of the mediation effect between AOC and ACC

According to the theoretical model, AOC can have effect on the ACC through three paths: $\mathrm{AOC} \rightarrow \mathrm{ACC}, \mathrm{AOC} \rightarrow \mathrm{EM} \rightarrow \mathrm{ACC}$ and $\mathrm{AOC} \rightarrow \mathrm{AOR} \rightarrow \mathrm{EM} \rightarrow \mathrm{ACC}$; Bootstrap was used to test the existence of the mediating effect of the three paths, and compare their mediating effect. The mediation effect between AOC and ACC is shown in Table 13.

Table 13. Test table of the mediation effect between AOC and ACC.

\begin{tabular}{|c|c|c|c|c|c|c|c|}
\hline \multirow{3}{*}{ Path Name } & \multirow{3}{*}{ Point Estimate } & \multirow{2}{*}{\multicolumn{2}{|c|}{ Product of Coefficients }} & \multicolumn{4}{|c|}{ Bootstrapping } \\
\hline & & & & \multicolumn{2}{|c|}{ BC $95 \%$ CI } & \multicolumn{2}{|c|}{ Percentile $95 \%$ CI } \\
\hline & & SE & $\mathbf{Z}$ & Lower & Upper & Lower & Upper \\
\hline \multicolumn{8}{|c|}{ Direct effect } \\
\hline $\mathrm{AOC} \rightarrow \mathrm{ACC}$ & 0.595 & 0.205 & 2.902 & 0.238 & 1.048 & 0.223 & 1.038 \\
\hline \multicolumn{8}{|c|}{ Indirect effects } \\
\hline EM & 0.068 & 0.092 & 0.739 & -0.105 & 0.261 & -0.103 & 0.267 \\
\hline AOR\&EM & 0.313 & 0.112 & 2.795 & 0.161 & 0.649 & 0.139 & 0.584 \\
\hline \multicolumn{8}{|c|}{ Total Effect } \\
\hline TOTAL & 0.975 & 0.241 & 4.046 & 0.572 & 1.528 & 0.563 & 1.513 \\
\hline
\end{tabular}

Note: $\mathrm{BC}$ is Bias-corrected; $\mathrm{CI}$ represents confidence interval; EM refers to path $\mathrm{AOC} \rightarrow \mathrm{EM} \rightarrow \mathrm{ACC}$; $\mathrm{AOR} \& \mathrm{EM}$ refers to path $\mathrm{AOC} \rightarrow \mathrm{AOR} \rightarrow \mathrm{EM} \rightarrow \mathrm{ACC}$; and samples were obtained by 5000 times of Bootstrap.

Table 13 indicates both $\mathrm{Z}$ values of the path $\mathrm{AOC} \rightarrow \mathrm{ACC}$ and $\mathrm{AOC} \rightarrow \mathrm{AOR} \rightarrow \mathrm{EM} \rightarrow \mathrm{ACC}$ are greater than 1.96, which means there are significant mediation effects on both paths based on the test with coefficient product method. Meanwhile, 0 is not contained in either minimal value or maximal value of the bias-corrected method and the percentile method. Therefore, we conclude that there is significant mediation effect of the influence path $\mathrm{AOC} \rightarrow \mathrm{AOR} \rightarrow \mathrm{EM} \rightarrow \mathrm{ACC}$ and significant direct effect of the influence path $\mathrm{AOC} \rightarrow \mathrm{ACC}$.

Meanwhile, the path $\mathrm{AOC} \rightarrow \mathrm{EM} \rightarrow \mathrm{ACC}$ has not been approved by coefficient multiplication method ( $Z$ value is less than 1.96), Bias-corrected method and Percentile method (0 is included between the minimum value and maximum value), which means the mediating effect of this path is not significant.

From the testing of mediating effect, it was found that the residents' AOC toward the water pollution caused by human activities cannot have positive effect on their motivation to protect water environment, but it has indirect positive effect on their acceptance toward the use of recycled water, so Assumption 7 is invalid. The residents' AOC toward the water pollution caused by human activities will have positive effect on their AOR of water pollution and motivation to protect water environment subsequently, and it has long-distance mediating effect on the acceptance degree, so Assumption 8 is valid. 


\subsection{Discussion}

Considering the use of recycled water can reduce environmental pollution and protect the environment, the use of recycled water can be regarded as a kind of pro-environmental behavior. Thus, the motivation of environmental protection should be considered when we researching the public's acceptance toward the use of recycled water. Moreover, NAM should be widely applied in the field to explain and predict the pro-environmental behaviors. Besides, self-completion theory can be used to improve NAM, while first-hand data can be used in the verification of assumptions.

\section{Conclusions}

Based on the above research, the following conclusions are drawn:

(1) NAM is applicable in the field that studies the acceptance behavior for the use of recycled water, and personal moral regulations could have positive effect on the use of recycled water. NAM has been used to interpret and predict numerous pro-environmental behaviors, while this study took the lead in using NAM to interpret the acceptance degree of the use of recycled water, and has achieved good outcomes. It also proved that personal moral norms influence the residents' acceptance toward the use of recycled water, which means the altruistic motivation that generates when people are making decision to use the recycled water is also an important influential factor that convinces others to accept the use of recycled water. Strengthening moral education and improving the citizens' moral awareness about water environment might an effective measure for the use of recycle water, other pro-environmental behaviors and technology promotion.

(2) It confirmed the path to activate individuals' moral norms in the protection of water environment, and found water pollution AOC will have indirect effect on the moral norms to protect water environment through the attribution of responsibility. Although the basic framework of NAM has long been recognized by the public, there are different opinions about the influence relation among AOC, AOR and moral obligations. In this study, firstly, different opinions were summarized, and then theoretical assumptions were proposed. Ultimately, it was found that the pollution AOR has positive effect on people's moral norms to protect the environment, while the AOC of pollution only has indirect effect on moral norms through AOR. This indicated that the activation path of moral norms has important effect on the acceptance to use recycled water and protect water environment, and also illustrated it is impossible to activate the public's moral norms to protect water environment if they only realize the consequence of water pollution caused by human activities: they must realize their personal responsibility to protect the environment and be aware of the consequence of pollution at the same time. This explained the path that activates the moral norms to protect water environment in detail and provided scientific reference to improve the public's moral norms as well as their acceptance to use recycled water.

(3) When people know the pollution that they bring to water environment, they will have a self-complete motivation, and it will improve their acceptance toward the use of recycled water. This study introduced self-complete theory into the typical theory model of NAM, and proposed the theory that AOC of water environment will have positive effect on the acceptance to use recycled water and confirmed the existence of the effect by testing the model fit and path coefficient. This conclusion has made improvements on the traditional NAM framework, and provided new thought for the use of recycled water, and the research fields of pro-environmental behavior and pro-social behaviors. The improved recycled NAM can be seen in Figure 5.

(4) The theoretical model confirmed the generation mechanism of the guiding effect of environmental protection motivation on the residents' in using recycled water, and provided scientific basis for making guiding policy to use recycled water. This study verified that improving residents' awareness of environmental crisis and to protect water environment are effective methods that affect their motivation to protect water environment, thus improving their acceptance to use recycled water. Consequently, a path has been proposed to improve the residents' motivation to protect environment, 
and embody it into the AOC and AOR of water pollution to provide scientific support for making policies to guide urban residents to use recycled water.

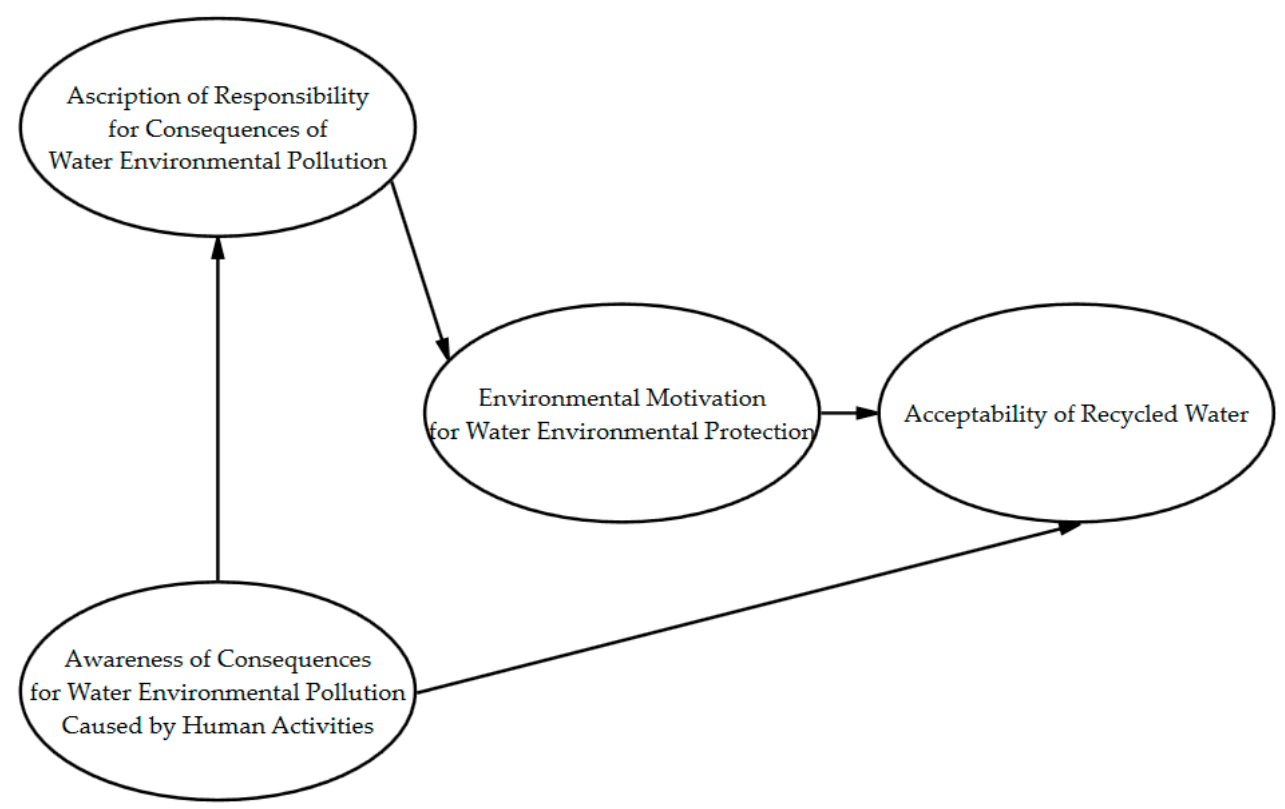

Figure 5. Logic frame diagram of improved recycled NAM.

Author Contributions: Conceptualization, X.L.; Methodology, H.F.; Software, H.F.; Validation, Y.H.; Formal Analysis, B.C. and Z.W.; Data Curation, M.W. and Z.W.; Writing-Original Draft Preparation, H.F. and Y.H.; Writing-Review and Editing, X.L. and Z.W.; Visualization, M.W. and Y.H.; Supervision, B.C.; Project Administration, X.L.; and Funding Acquisition, X.L.

Funding: Funding was acquired from Chinese Postdoctoral Science Foundation (Project No. 2018M633480) and MOE (Ministry of Education in China) Project of Humanities and Social Sciences (Project No. 18YJA630068).

Acknowledgments: This work was supported by the MOE Project of Humanities and Social Sciences (Project No. 18YJA630068) and the Chinese Postdoctoral Science Foundation "Research on the influencing factors and driving strategies of urban residents' recycled water reuse behaviors" (Project No. 2018M633480).

Conflicts of Interest: The authors declare no conflict of interest.

\section{References}

1. Veldkamp, T.; Wada, Y.; Aerts, J.; Döll, P.; Gosling, S.; Liu, J.; Masaki, Y.; Oki, T.; Ostberg, S.; Pokhrel, Y.; et al. Water scarcity hotspots travel downstream due to human interventions in the 20th and 21st century. Nat. Commun. 2017, 8, 15697. [CrossRef] [PubMed]

2. Lu, S.; Zhang, X.; Bao, H.; Skitmore, M. Review of social water cycle research in a changing environment. Renew. Sustain. Energy Rev. 2016, 63, 132-140. [CrossRef]

3. Liu, H.; Fang, C.; Zhang, X.; Wang, Z.; Bao, C.; Li, F. The effect of natural and anthropogenic factors on haze pollution in Chinese cities: A spatial econometrics approach. J. Clean. Prod. 2017, 165, 323-333. [CrossRef]

4. Zhu, Z.; Li, A.; Wang, H. Public perception and acceptability of reclaimed water: The case of Shandong province, China. J. Water Reuse Desalin. 2017, 8. [CrossRef]

5. Fu, H.; Li, Z.; Liu, Z.; Wang, Z. Research on Big Data Digging of Hot Topics about Recycled Water Use on Micro-Blog Based on Particle Swarm Optimization. Sustainability 2018, 10, 2488. [CrossRef]

6. Fielding, K.; Gardner, J.; Leviston, Z.; Price, J. Comparing Public Perceptions of Alternative Water Sources for Potable Use: The Case of Rainwater, Stormwater, Desalinated Water, and Recycled Water. Water Resour. Manag. 2015, 29, 4501-4518. [CrossRef]

7. Kajenthira, A.; Siddiqi, A.; Anadon, L. A new case for promoting wastewater reuse in Saudi Arabia: Bringing energy into the water equation. J. Environ. Manag. 2012, 102, 184-192. [CrossRef] [PubMed] 
8. Liu, Z.; Cheng, K.; Li, H.; Cao, G.; Wu, D.; Shi, Y. Exploring the potential relationship between indoor air quality and the concentration of airborne culturable fungi: A combined experimental and neural network modeling study. Environ. Sci. Pollut. Res. 2018, 25, 3510-3517. [CrossRef] [PubMed]

9. Gu, Q.; Chen, Y.; Pody, R.; Cheng, R.; Zheng, X.; Zhang, Z. Public perception and acceptability toward reclaimed water in Tianjin. Resour. Conserv. Recycl. 2015, 104, 291-299. [CrossRef]

10. Miao, R.; Wang, L.; Feng, L.; Liu, Z.; Lv, Y. Understanding PVDF ultrafiltration membrane fouling behaviour through model solutions and secondary wastewater effluent. Desalin. Water Treat. 2014, 52, 5061-5067. [CrossRef]

11. Araral, E.; Wang, Y. Does Water Governance Matter to Water Sector Performance? Evidence from 10 Provinces in China. Water Policy 2015, 17, 268-282. [CrossRef]

12. Fu, H.; Liu, Z.; Wang, M.; Wang, Z. Big Data Digging of Public's Cognition about Recycled Water Reuse based on BP Neural Network. Complexity 2018. Available online: https:/ /www.hindawi.com/journals/ complexity /aip/1876861/ (accessed on 19 September 2019).

13. West, C.; Kenway, S.; Hassall, M.; Yuan, Z. Why do residential recycled water schemes fail? A comprehensive review of risk factors and impact on objectives. Water Res. 2016, 102, 271-281. [CrossRef] [PubMed]

14. Zhang, Q.; Yang, W.; Ngo, H.; Guo, W.; Jin, P.; Dzakpasu, M.; Yang, S.; Wang, Q.; Wang, X.; Ao, D. Current status of urban wastewater treatment plants in China. Environ. Int. 2016, 92-93, 11-22. [CrossRef] [PubMed]

15. Gibson, F.L.; Burton, M. Salt or sludge? Exploring preferences for potable water sources. Environ. Resour. Econ. 2013, 57, 453-476. [CrossRef]

16. Qian, N.; Leong, C. A game theoretic approach to implementation of recycled drinking water. Desalin. Water Treat. 2016, 57, 1-9. [CrossRef]

17. Wester, J.; Timpano, K.R.; Çek, D.; Broad, K. The psychology of recycled water: Factors predicting disgust and willingness to use. Water Resour. Res. 2016, 52, 3212-3226. [CrossRef]

18. Fu, H.; Liu, X. Research on the Phenomenon of Chinese Residents' Spiritual Contagion for the Reuse of Recycled Water Based on SC-IAT. Water 2017, 9, 846.

19. Zhang, B.; Fu, H. Effect of guiding policy on urban residents' behavior to use recycled water. Desalin. Water Treat. 2018, 114, 93-100. [CrossRef]

20. Mankad, A.; Tapsuwan, S. Review of socio-economic drivers of community acceptance and adoption of decentralised water systems. J. Environ. Manag. 2011, 92, 380-391. [CrossRef] [PubMed]

21. Inbar, Y.; Pizarro, D.; Iyer, R.; Haidt, J. Disgust sensitivity, political conservatism, and voting. Soc. Psychol. Personal. Sci. 2011, 3, 537-544. [CrossRef]

22. Wen, R.; Banik, B.; Pathak, R.K.; Kumar, A.; Kolishetti, N.; Dhar, S. Nanotechnology inspired tools for mitochondrial dysfunction related diseases. Adv. Drug Deliv. Rev. 2016, 99, 52-69. [CrossRef] [PubMed]

23. Yang, A.; Han, Y.; Pan, Y.; Xing, H.; Li, J. Optimum surface roughness prediction for titanium alloy by adopting response surface methodology. Results Phys. 2017, 7, 1046-1050. [CrossRef]

24. Ormerod, K.J.; Scott, C.A. Drinking wastewater: Public trust in potable reuse. Sci. Technol. Hum. Values 2012, 38, 351-373. [CrossRef]

25. Fu, H.; Liu, X. A Study on the Impact of Environmental Education on Individuals' Behaviors Concerning Recycled Water Reuse. EURASIA J. Math. Sci. Technol. Educ. 2017, 13, 6715-6724. [CrossRef]

26. Nancarrow, B.; Leviston, Z.; Tucker, D. Measuring the predictors of communitie' behavioural decisions for potable reuse of wastewater. Water Sci. Technol. 2009, 60, 3199-3209. [CrossRef] [PubMed]

27. Kollmuss, A.; Agyeman, J. Mind the Gap: Why do people act environmentally and what are the barriers to pro-environmental behavior? Environ. Educ. Res. 2002, 8, 239-260.

28. Liu, W.; Xu, J.; Li, J. The Influence of Poverty Alleviation Resettlement on Rural Household Livelihood Vulnerability in the Western Mountainous Areas, China. Sustainability 2018, 10, 2793. [CrossRef]

29. Miao, R.; Wang, L.; Wang, X.; Lv, Y.; Gao, Z.; Mi, N.; Liu, T. Preparation of a polyvinylidene fluoride membrane material probe and its application in membrane fouling research. Desalination 2015, 357, 171-177. [CrossRef]

30. Miao, R.; Wang, L.; Mi, N.; Gao, Z.; Liu, T.; Lv, Y.; Wang, X.; Meng, X.; Yang, Y. Enhancement and Mitigation Mechanisms of Protein Fouling of Ultrafiltration Membranes under Different Ionic Strengths. Environ. Sci. Technol. 2015, 49, 6574-6580. [CrossRef] [PubMed]

31. Liu, T.; Liu, H.; Chen, Z.; Lesgold, A.M. Fast Blind Instrument Function Estimation Method for Industrial Infrared Spectrometers. IEEE Trans. Ind. Inform. 2018. [CrossRef] 
32. Chen, W.; Feng, Q.; Zhang, G.; Yang, Q. Investigations on flotation separation of scheelite from calcite by using a novel depressant: Sodium phytate. Miner. Eng. 2018, 126, 116-122. [CrossRef]

33. Cheng, Y.; Li, Y.; Huang, T.; Sun, Y.; Shi, X.; Shao, Y. A comparison study of the start-up of a MnOx filter for catalytic oxidative removal of ammonium from groundwater and surface water. J. Environ. Sci. 2018, 65, 327-334. [CrossRef] [PubMed]

34. Miao, R.; Wu, Y.; Wang, P.; Wu, G.; Wang, L.; Li, X.; Wang, J.; Lv, Y.; Liu, T. New insights into the humic acid fouling mechanism of ultrafiltration membranes for different $\mathrm{Ca}^{2+}$ dosage ranges: Results from micro- and macro-level analyses. Water Sci. Technol. 2018, 77, 2265-2273. [CrossRef] [PubMed]

35. Jiang, S.; Lian, M.; Lu, C.; Gu, Q.; Ruan, S.; Xie, X. Ensemble Prediction Algorithm of Anomaly Monitoring Based on Big Data Analysis Platform of Open-Pit Mine Slope. Complexity 2018, 2018, 1048756. [CrossRef]

36. Wang, B.; Chen, W.; Wang, J.; Zhang, B.; Zhang, Z.; Qiu, X. Cooperative Tracking Control of Multi-agent Systems: A Heterogeneous Coupling Network and Intermittent Communication Framework. IEEE Trans. Cybern. 2018. [CrossRef]

37. Wen, Z.; Wang, Y.; Djavan, D. What is the true value of food waste? A case study of technology integration in urban food waste treatment in Suzhou City, China. J. Clean. Prod. 2016, 118, 88-96. [CrossRef]

38. Schwartz, S.; Howard, J. A normative decision-making model of altruism. In Altruism and Helping Behavior; Rushton, J.P., Sorrentino, R.M., Eds.; Erlbaum: Hillsdale, MI, USA, 1981; pp. 189-211.

39. Christina, M.; Fehr, J.; Sassenberg, K. When does goal discrepancy induce compensatory effort? An application of self-completion theory to social issues. Soc. Personal. Psychol. Compass 2012, 6, 536-550.

40. Jordan, J.; Mullen, E.; Murnighan, J. Striving for the moral self: The effects of recalling past moral actions on future moral behavior. Personal. Soc. Psychol. Bull. 2011, 37, 701-713. [CrossRef] [PubMed]

41. Hu, M.; Horng, J.; Teng, C.; Chiou, W.; Yen, C. Fueling Green Dining Intention: The Self-Completion Theory Perspective. Asia Pac. J. Tour. Res. 2014, 19, 793-808. [CrossRef]

42. Chaisamrej, R.; Zimmerman, R. Comparative Investigation of TPB and Altruism Frameworks for an empirically based Communication Approach to Enhance Paper Recycling. Appl. Environ. Educ. Commun. 2014, 13, 28-37. [CrossRef]

43. Wang, Y.; Mukherjee, M.; Wu, D.; Wu, X. Combating River Pollution in China and India: Policy Measures and Governance Challenges. Water Policy 2016. [CrossRef]

44. Liu, K.; Fu, H.; Chen, H. Research on the Influencing Mechanism of Traditional Cultural Values on Citizens' Behavior Regarding the Reuse of Recycled Water. Sustainability 2018, 10, 165. [CrossRef]

45. Jiang, W.; Zipp, K.Y.; Jacobson, M. Economic assessment of landowners' willingness to supply energy crops on marginal lands in the northeastern of the United States. Biomass Bioenergy 2018, 113, 22-30. [CrossRef]

46. Hurlimann, A.; Dolnicar, S. Public acceptance and perceptions of alternative water sources: A comparative study in nine locations. Int. J. Water Resour. Dev. 2016, 32, 650-673. [CrossRef]

47. Tan, G.W.H.; Ooi, K.B. Gender and age: Do they really moderate mobile tourism shopping behavior? Telemat. Inform. 2018, 35, 1617-1642. [CrossRef]

48. Wang, Z.; Wang, X.; Tonga, Y.; Wang, Y. Impact of structure and flow-path on in situ synthesis of AlN: Dynamic microstructural evolution of Al-AlN-Si materials. Sci. China Mater. 2018, 61, 948-960. [CrossRef]

49. Jacobson, M.; Jiang, W. Newbio: Growing bioenergy on marginal lands. In Proceedings of the 13th North American Agroforestry Conference, Charlottetown, PE, Canada, 19-21 June 2013; Agriculture \& Agri-Food Canada: Guelph, ON, Canada, 2013; pp. 44-48.

50. Liu, X.; Wang, M.; Fu, H. Visualized analysis of knowledge development in green building based on bibliographic data mining. J. Supercomput. 2018. [CrossRef]

51. Onwezen, M.; Antonides, G.; Bartels, J. The norm activation model: An exploration of the functions of anticipated pride and guilt in pro-environmental behaviour. J. Econ. Psychol. 2013, 39, 141-153. [CrossRef]

52. Chen, L.; Tang, M.; Chen, C.; Chen, M.; Luo, K.; Xu, J.; Zhou, D.; Wu, F. Efficient Bacterial Inactivation by Transition Metal Catalyzed Auto-Oxidation of Sulfite. Environ. Sci. Technol. 2017, 51, 12663-12671. [CrossRef] [PubMed]

53. Sun, F.; Yao, Y.; Li, X. The Heat and Mass Transfer Characteristics of Superheated Steam Coupled with Non-condensing Gases in Horizontal Wells with Multi-point Injection Technique. Energy 2018, 143, 995-1005. [CrossRef]

54. Bentler, P.; Bonett, D. Significance tests and goodness of fit in the analysis of covariance structure. Psychol. Bull. 1980, 88, 588-606. [CrossRef] 
55. Cui, P.; Tonnemacher, M.; Rajan, D.; Camp, J. WhiteCell: Energy-efficient use of unlicensed frequency bands for cellular offloading. In Proceedings of the 2015 IEEE International Symposium on Dynamic Spectrum Access Networks (DySPAN), Stockholm, Sweden, 29 September-2 October 2015; IEEE: Piscataway, NJ, USA, 2015; pp. 188-199.

56. Hair, J.; Anderson, R.; Tatham, R.; Black, W. Multivariate Data Analysis, 5th ed.; Prentice Hall: Upper Saddle River, NJ, USA, 1998; pp. 677-679.

57. Fornell, C.; Larcker, D. Evaluating structural equation models with unobservable variables and measurement error. J. Mark. Res. 1981, 18, 39-50. [CrossRef]

58. Jackson, D.; Gillaspy, J.; Purcstephenson, R. Reporting practices in confirmatory factor analysis: An overview and some recommendations. Psychol. Methods 2009, 14, 6-23. [CrossRef] [PubMed]

59. Little, T. Mean and covariance structures (MACS) analyses of cross-cultural data: Practical and theoretical issues. Multivar. Behav. Res. 1997, 32, 53-76. [CrossRef] [PubMed]

60. Rucker, D.; Preacher, K.; Tormala, Z.; Petty, R. Mediation Analysis in Social Psychology: Current Practices and New Recommendations. Soc. Personal. Psychol. Compass 2011, 5, 359-371. [CrossRef]

61. Hayes, A. Beyond Baron and Kenny: Statistical Mediation Analysis in the New Millennium. Commun. Monogr. 2009, 76, 408-420. [CrossRef]

(C) 2018 by the authors. Licensee MDPI, Basel, Switzerland. This article is an open access article distributed under the terms and conditions of the Creative Commons Attribution (CC BY) license (http:/ / creativecommons.org/licenses/by/4.0/). 